\title{
Author Correction: The contribution of predators and scavengers to human well-being
}

Christopher J. O'Bryan (1), Alexander R. Braczkowski, Hawthorne L. Beyer, Neil H. Carter, James E. M. Watson and Eve McDonald-Madden

Correction to: Nature Ecology \& Evolution https://doi.org/10.1038/s41559-017-0421-2, published online 18 January 2018.

In the version of this Review originally published, there were a number of errors that the authors wish to correct.

The silhouette of the barn owl used throughout was that of a different owl; this has been replaced with the correct silhouette. Reference 52 was mistakenly cited in Table 1; this has been removed. The text in the third column of the fifth row in Table 1 was incorrectly written as "Barn owls consume $>99 \%$ of crop pests and reduce rodent density by over $33 \%$ in alfalfa fields"; it should have read: 'Barn owls consume $>99 \%$ of rodent pests in row crops of California, USA.' (Note that due to the changes in the text, references for numbers 51 and 52 have now swapped over.)

There were also several errors in the section 'Predators can indirectly increase agricultural output'. The end of the second paragraph was missing the following text: 'Additionally, insectivorous birds can reduce weevil density by over $33 \%$ in alfalfa fields of central California, USA ${ }^{51}$. The second sentence of the third paragraph was slightly incorrect; "and reduces rodent density by over $33 \%$ in the

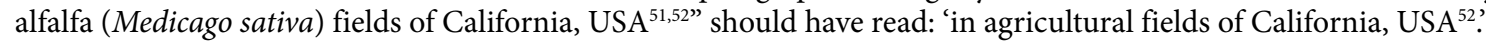

All these errors have now been corrected in all versions of the Review. 